\title{
La melancolía de Calisto
}

\author{
Bienvenido Morros Mestres \\ Universidad Autónoma de Barcelona
}

La crítica ha creído que el personaje de Calisto experimenta un cambio de temperamento que justifica por el hecho de haber sido rechazado por Melibea. Otro personaje ilustre de la literatura universal, Hamlet, también había padecido una transformación similar después de conocer que su padre había sido asesinado por su propio hermano. En las dos obras los personajes en cuestión sucumben a una melancolía que se la producen dos sucesos muy importantes en sus vidas ${ }^{1}$. Por lo que respecta a Calisto, antes de ese rechazo parecía tener un temperamento muy diferente al que exhibirá a lo largo de los veintiún actos. La crítica le había atribuido un temperamento colérico, propio de personas nobles e ilustres ${ }^{2}$. En la primera escena podía aún hacer gala de ese primer temperamento al abordar a una Melibea con la que se ha encontrado casualmente. En esa cita inicial dedica a su dama los mayores elogios al considerarla no sólo como obra de maestra de Dios, sino también como Dios mismo de cuya contemplación goza al igual que lo hacen la Virgen María o Jesucristo en el paraíso ${ }^{3}$. Da a entender que esa situación de privilegio la ha conseguido por sus oraciones, obras de caridad y limosnas realizadas en un pasado que no sabemos si es inmediato o remoto. No cree que ese premio que ha pedido con tanta insistencia a Dios fuese mayor que el que pudiera concederle al asignarle un lugar en el paraíso entre los propios santos. Entre tantas imágenes teológicas no puede disimular su lascivia de la que Melibea se ha percatado al echarlo del lugar en que se han encontrado llamándole "torpe», que es un latinismo que significa 'lujurioso'. Sólo por ese dato podemos concluir que el temperamento de Calisto es colérico o sanguíneo, que tienen en común la gran la lujuria que sienten quienes los

\footnotetext{
1.- A esas conclusiones llega Fraker 1993.

2.- Véase Fraker 1993.

3.- Para ese tema véase Castells 1993 y Morros 2009.
} 
son, a diferencia de los otros dos temperamentos, el flemático y el melancólico, que en su estado natural no la llegan a sufrir ${ }^{4}$. Tras ser despedido por su dama, nuestro héroe regresa a su casa a cuya llegada reclama a gritos la presencia de Sempronio, al que pregunta dónde está, por no verlo en ninguna parte. Al advertir una clara contradicción entre la labor que decía estar llevando a cabo y el aposento del que sale su criado, se enfurece aún más deseándole una muerte violenta, como presagiando ese trágico final del criado antes que la suya, de características similares. Tras calmarse un poco, le pide a Sempronio que cierre las ventanas de su dormitorio para poder en su interior quedarse a solas y en la más absoluta oscuridad. Sin embargo, no tarda mucho tiempo en requerir la presencia de su criado porque necesita su compañía para poder desahogarse. No parece haberse convertido aún en un melancólico absoluto, porque no acaba de adaptarse a la soledad. El criado, antes de entrar en el dormitorio, se pregunta a sí mismo a qué se debe ese cambio tan súbito que ha notado en su amo. Al salir de casa lo había visto alegre como siempre y al regresar enfadado y triste como nunca. Repara en esos dos Calistos tan diferentes que todavía no se explica porque ignora el suceso que los ha propiciado.

En esas dos escenas, tanto el antiguo autor como Rojas no han empleado la palabra melancolía pero han atribuido síntomas de la enfermedad a su protagonista, que no han querido confirmar quizá para eludir la responsabilidad de hacérsela padecer de manera contundente. El antiguo autor, en cambio, había querido presentar a Calisto víctima del amor hereos porque le hace invocar al médico que se la había diagnosticado al hijo de Seleuco, enamorado de su madrastra Estratonice. Si invoca a Erasístrato es porque deseaba que viviera un médico que fuera capaz de descubrir su enfermedad y aplicarle la misma terapia sexual canalizada a través del matrimonio con su madrastra, después de que su padre se la hubiera cedido para devolverle la salud perdida a su hijo ${ }^{5}$. Con esa referencia

4.- Para el comportamiento sexual de cada uno de los cuatro temperamentos que la medicina clásica llegó a distinguir, véase Morros 2009.

5.- No entiendo cómo algunos autores se resisten a admitir que Calisto está recordando la anécdota que protagoniza Erasístrato con el rey Seleuco, porque cree que su caso es de la misma índole que el del príncipe y Antíoco y porque desea también la misma solución. Por más que se hayan documentado a dos médicos con los nombres de Eras y Crato, no fueron demasiado conocidos en la profesión que desempeñaron ni tampoco se dedicaron a la especialidad a la que Calisto está aludiendo para que el médico a quien querría vivo sea capaz de diagnosticarle su enfermedad. A Rojas pudo haberle llegado una versión de los papeles que halla en Salamanca con el error paleográfico de "Eras y Strato» (o "Eras y Trato»), y que en la Tragicomedia corrige por "Eras y Galeno", porque había leído el Lilio de medicina en que Gordonio menciona la que protagonizó el segundo también como especialista en la enfermedad. De haber querido suprimir la lectura del «antiguo autor», podía haber pensado en un solo médico, el de Galeno, que diagnostica un caso de amor hereos por el mismo método de tomarle el pulso a la enferma, pero en el que, a diferencia de su colega, no ofrece la solución del matrimonio para su paciente. Creo que en su original se encuentra con el error que produce 
el anónimo autor quería dejar claro que su personaje era un enfermo de amor al que desde ese momento lo caracteriza con el síntoma que confirma que ya lo ha llegado a ser. Es el criado el encargado de destacarlo al recordarle a su amo que contempla a Melibea con unas lentes de aumento que convierten sus cualidades, seguramente muy discretas, en otras que la igualan con las diosas más bellas. Le anuncia que sólo seduciéndola podrá reconocer en su dama los defectos que en ese momento le niega por efecto del mal funcionamiento de uno de sus sentidos internos. Para entretenerse el señor pide al criado un laúd con que acompañarle con su desafinada música el canto del romance del incendio de Roma por Nerón. Siente la tentación de glosarlo para llegar a la conclusión de que el fuego en el que arde es mucho mayor que el que quemó a los habitantes de toda una ciudad. Asegura que si el fuego del purgatorio es como el que le quema en ese momento prefiere desaparecer como los brutos animales renunciando de ese modo a la inmortalidad de su alma. Al insistir tanto en ese elemento que altera su complexión podía estar apuntando a un temperamento colérico, que siempre se ha asociado con el fuego, caliente y seco ${ }^{6}$.

Sempronio considera que la terapia más eficaz para sanar a su amo es la de tipo sexual. Por eso le recomienda contratar los servicios de una alcahueta capaz incluso de provocar a lujuria a las piedras. Sale en su busca y deja a su amo en compañía de Pármeno, con quien no puede reprimir una ira moderada al oírle desaprobar los métodos que ha decidido utilizar para conseguir a Melibea. Al recibir a Celestina, da muestras de una gran liberalidad al entregarle cien monedas de oro como adelanto por su trabajo. Esas no son conductas propias de un melancólico, a quien se le solía atribuir cierta tacañería ${ }^{7}$. Tras la marcha de la alcahueta, consulta con sus dos criados si ha procedido correctamente haciendo lo que ha hecho. Ordena a Sempronio que siga a Celestina para que la urja a cumplir cuanto antes con su tarea. Vuelve a quedarse a solas con Pármeno, a quien, por no soportar sus buenos consejos, decide abandonar saliendo de paseo en uno de sus caballos para pasar por delante de la casa de Melibea. En esa actitud, tampoco parece comportarse como un melancólico, pues tiene la fuerza de ánimo suficiente para acercarse al lugar de donde su dama lo había echado con gran vehemencia. Cuando vuelve a aparecer en escena lo hace de nuevo en su casa para recibir por segunda vez a la alcahueta, que ha estado en casa de Pleberio para poner en práctica el conjuro que ha urdido para su hija. De esa entrevista con la doncella ha obtenido muy buenos resultados, porque Celestina ha

el desdoblamiento de un médico en dos, y ante cierto desconcierto, por ignorar el episodio al que alude el anónimo autor, opta en un primer momento por mantener el texto tal y como lo halla copiado. Sólo en la revisión de la Comedia se atreve a introducir el nombre de Galeno porque lo considera muy pertinente al haber leído lo que Gordonio dice de él.

6.- A esa conclusión llega De Armas 1995.

7.- Es el rasgo que de ese temperamento ofrece el Arcipreste de Talavera, 
empleado el eufemismo del dolor de muelas de su cliente para provocar la connivencia de Melibea, de cuya casa sale con el valioso trofeo de su cordón, una prenda íntima que hacía presagiar el éxito de su empresa y la eficacia del conjuro. Al tenerlo entre sus manos, Calisto vuelve a excitarse porque lo trata de tal manera, que está a punto de romperlo por confundirlo con su dueña, con quien se imagina estar satisfaciendo su deleite carnal. Curiosamente, después de esa exaltación de lujuria que le provoca la posesión del cordón, se sume en un estado de semiinconsciencia que no le permite distinguir cuándo es de día y cuándo de noche. Se ha pasado desde la tarde en que ha vuelto a ver a Celestina hasta el mediodía del día siguiente tumbado en la tarima sobre la que descansa su cama. La abulia la ha alternado con algunas canciones de amor que no ha entonado con la mejor de las voces. A las doce decide dejar su dormitorio para dirigirse a la misa de esa hora en la iglesia de la Magdalena en la que pasará el resto del día pidiendo a Dios que guíe a la alcahueta en la consecución de su fin. En la Iglesia lo van han encontrar por la tarde cuando lo recogen una exultante Celestina y unos escépticos criados para anunciarle que la primera ha conseguido una cita con Melibea en la puerta de su casa a las doce de la noche. A pesar de las buenas noticias que le ha dado la alcahueta, Calisto sigue incurriendo en las mismas herejías que al principio, cuando asegura que Melibea es un ángel infiltrad entre la raza humana y por tanto sin la mala intención que le atribuyen sus dos criados. En ese caso recompensa a Celestina con una cadena de oro, y decide dormir un rato hasta que llegue la hora de la cita. Cuando despierta no puede reprimir cierta ira con sus criados al comprobar que, al preguntarles la hora, Sempronio le contesta que son las diez cuando él ha oído que el reloj de la iglesia había dado ya once campanadas.

Para llegar ante la puerta de entrada de la casa de Melibea han adoptado todo tipo de precauciones. Se acerca él solo para poder dialogar con su amada a través de la gruesa puerta, que habría mandado derribar a sus criados de no haberle disuadido Melibea a que lo hicieran para no despertar con el ruido a sus padres o para no dejar pruebas de una relación que, con la puerta destrozada, no habrían podido mantener en secreto. Por satisfacer la lujuria, Calisto está dispuesto a superar todos los obstáculos, sin reparar en las consecuencias que una actitud tan impulsiva podría ocasionar a los dos. Melibea lo emplaza para la noche siguiente en su jardín, al que sugiere llegar saltando las paredes que lo rodean. Esa noche Calisto la puede dormir de un tirón sin padecer ningún tipo de pesadilla ni de insomnio. El descanso lo atribuye a la fatiga de la última noche o a la desaparición del pensamiento obsesivo hacia su dama ante la seguridad de que la podrá seducir muy pronto. A pesar de ese síntoma de mejoría, al despedirse de Melibea, ha insistido en sus herejías de siempre al considerar el acto sexual que llevarán a cabo la noche siguiente no como un pecado sino como una acción que Dios permite porque se la había 
pedido con sus oraciones en la iglesia de la Magdalena. Poco o mucho aún sigue enajenado.

Sin embargo, en medio de tanta felicidad, recibe la trágica noticia del asesinato de Celestina y la ejecución de sus dos criados homicidas. En ese momento tiene la prioridad de llevar a cabo sus planes de reunirse, según lo previsto, por la noche con su amada. Para no alterarlos decide pasar el día encerrado en su casa a la espera de salir para dirigirse al huerto de su amada. Si obra así es para dar a entender que ha estado fuera de la ciudad y para que no lo relacionen directamente con el asesinato de Celestina, de cuya noticia quiere aparentar ignorancia. Acompañado por dos nuevos criados, mucho más valientes que sus compañeros, Calisto sube por las escaleras que previamente Tristán ha apoyado en la pared. Cuando ha llegado a lo alto del muro coge la escalera para apoyarla por el otro lado y bajar hasta el huerto. Al divisar a su dama parece descender de manera tan precipitada, que incluso Melibea teme por su integridad física. Al llegar a su altura obra con suma descortesía al desnudarla sin ningún tipo de miramiento y sin hacer ningún caso a las protestas de la aún doncella a la que se dispone a rendir sexualmente. Argumenta que en toda su vida no había deseado otra cosa que la que está poniendo en ejecución en ese momento, y que, estando en condiciones de consumarla, no se abstendrá, porque su lujuria es tal, que, aunque lo intentara, no podría conseguirlo. Sigue diciendo que no conoce otro modo de curar la enfermedad que lo ha torturado estos días. Le dice que si renuncia a la posesión sexual volverá a pasar por un calvario que quiere evitar a toda costa. Por eso no interrumpe su acción de quitarle la ropa a Melibea y sin más preámbulos arrebatarle la tan preciada virginidad. Melibea, ante la inquebrantable voluntad de su amante, pide a Lucrecia que se aleje para no convertirse en testigo de lo que parece que querría haber evitado. Calisto, en cambio, desea que se quede, infringiendo la norma sagrada de cualquier amante cortés de ocultar no sólo sus sentimientos sino también los servicios realizados por la amada. Ante la consumación de los hechos, Melibea lamenta haber perdido un preciado tesoro que nadie le puede restituir, pues quien podía hacerlo ha muerto. Los amantes han oído al reloj de la iglesia dar tres campanadas y saben que pronto amanecerá, por lo que deben separarse. Melibea le pide, ya que ha dejado de ser doncella, que vuelva a la noche siguiente, dando muestras de haber superado el enojo por la conducta de Calisto.

Al volver a su dormitorio, Calisto no se siente alegre como cabía esperar después de haber seducido a la mujer de sus sueños. Reconoce apetecerle no sólo el silencio y la soledad del lugar en que se halla, sino también la solicitud que no ha dejado de sentir ni con la satisfacción del deseo que se la causaba. Esa es una palabra que se usa especialmente en los libros de medicina para definir la angustia e inquietud de ciertas enfermedades 
mentales 8 . Suele incluirse en las definiciones de la melancolía y del amor hereos, pero en determinados textos podía emplearse como denominador común de las dos enfermedades al identificar la segunda como "solicitud melancólica». Calisto, sin embargo, la menciona sin ese adjetivo, porque por el momento pretende subrayar que es objeto de una angustia similar a la que había experimentado después de haber sido rechazado por su dama. No acaba de explicarse una depresión que le invade cuando estaba convencido de no volverla a padecer tras haber hecho realidad el sueño de poseer sexualmente a Melibea ${ }^{9}$. La intenta justificar por la ejecución de sus dos criados sobre quienes el juez había dictado una sentencia de muerte. Reprocha primero al juez no haber perdonado a sus criados recordando favores que le debía por el tiempo en que estuvo al servicio de su padre. Después entiende que no lo hubiera hecho por estar los condenados ya moribundos como consecuencia del salto que dieron desde la ventana de la casa de la alcahueta cuando huían de la justicia. Incluso alaba su actuación de hacer cumplir la sentencia al alba para evitar dar publicidad a un suceso que de ese modo habría pasado más desapercibido en la ciudad. Tras esas reflexiones vuelve a conceder prioridad a Melibea exigiendo a su fantasía que le reproduzca las escenas de pasión que ha protagonizado con ella unas horas antes. En tales recuerdos parece estar exagerando la conducta de su dama al atribuirle unas efusiones que sin duda no se desprendían de los reproches que dedicaba a su amante por sus modales tan groseros ${ }^{10}$. Posiblemente siga contemplando a Melibea

8.- En algunas ediciones aparece sustituida por «soledad», que parece un error por lectio facilior, aún más explicable si se supone otro anterior de "solitud» por "solicitud» (véase Seres y Lobera, en Rojas 2000). En su definición de amor hereos, Gordonio esta palabra la había hecho acompañar del adjetivo "melancólica» para insistir en la relación de las dos enfermedades, pero Valesco de Taranta la emplea sin el adjetivo para desvincularlas y no presentarlas desde un principio con una conexión evidente. Si Rojas, que también conocía el texto de Gordonio (Morros 2009), suprime el adjetivo puede o no ser con intención. Yo creo, como afirmo más abajo, que nuestro autor lo hace con intención para evitar caracterizar a Calisto con ese temperamento al que al médico que toma como modelo le había negado una lujuria de la que quiere dotar a su protagonista.

9.- Algunos médicos justificaban la tristeza después del coito por no haberse alimentado de forma debida en las horas previas a su realización (Morros 2009). En el caso de Rojas sabemos que ha dormido hasta muy tarde y no hace ninguna referencia a que haya comido después de haberse levantado y antes de acudir a la cita con su su amada. En el transcurso de sus relaciones sexuales se niega a comer y beber porque piensa que ésas son actividades que pueden llevar a cabo en cualquier parte, pero lo que está poniendo en práctica en el huerto de Melibea sólo puede cumplirlo en ese lugar y no en otro. En todos los modelos de la escena, los amantes implicados, sea Amadís, Euríalo o Tirant, aceptan ese refrigerio para recuperar las fuerzas perdidas. Los tres, al final de ese primer encuentro sexual con sus amadas, quedan contentos y más enamorados de sus damas.

10.- En la Historia de duobus amantibus, Euríalo abandona feliz a Lucrecia después de haberla seducido y comparte esa alegría con uno de sus amigos al que describe las escenas eróticas que acaba de disfrutar aportando detalles que el narrador no había ofrecido en el momento de relatarlas: «¡Oh miembros como mármol, de zumo llenos! ¿Cuándo os tornaré a ver? ¿Cuándo 
con los mismos «ojos de alinde» que al principio de la obra, porque da la impresión de estar magnificando la pasión exhibida por su dama en unas escenas de sexo que su memoria podía estar alterando por su mal funcionamiento. Se sentía quizá defraudado al no haberse cumplido el pronóstico de los médicos que garantizaban la curación de amor hereos con una terapia sexual que podía ser más eficaz si se practicaba con la dama que lo había causado. Es obvio que a él esa terapia no le ha producido el efecto esperado, porque no ha conseguido olvidar a una Melibea que en su mente se la representa más lujuriosa de lo que en realidad había sido. Continúa alimentando la misma lujuria que al principio al imaginar a su dama proporcionándole el placer sexual que había anhelado la primera vez que la vio. Para algunos críticos, Calisto con este monólogo demuestra haber cambiado porque deja de adoptar las actitudes grotescas de antaño para asumir otras mucho más serías ${ }^{11}$. Antes de seducir a Melibea podía haber fingido una locura que no padecía para conseguir su propósito (Villalobos denuncia ese comportamiento en muchos galanes ${ }^{12}$ ), pero, una vez alcanzado, se habría enamorado de verdad de la dama con la que sólo esperaba divertirse. En los cinco autos interpolados sólo vuelve a aparecer para protagonizar una escena de amor muy similar a la de un mes antes. Por eso no hay demasiados indicios para corroborar un cambio que podía haberse producido pero que es muy difícil de demostrar.

En el último encuentro con Melibea en su huerto Calisto no ha variado sus modales, que siguen provocando las protestas de su amada, que

otra vez los labrios de coral morderé? ¿Cuándo la lengua parlando otra vez a mi boca bullir sentiré? ¡Oh si trataré más aquellas tetillas!» (Piccolomini 2001: 198). La técnica es la misma que usa Rojas al poner en boca de Calisto al final de su monólogo después de ese primer encuentro sexual con Melibea unas actitudes que ni él ni su amada parecen llevar a cabo cuando las acometen, al menos según se deduce por el diálogo que llegan a intercambiar los dos amantes. Si Euríalo recuerda unas escenas que sí ha protagonizado, Calisto, en cambio, se las inventa porque su locura le lleva a imaginar a una Melibea no sólo muy satisfecha, sino muy activa sexualmente. Uno de los engaños que padece el amante hereos es el de pensar que sólo la amada elegida como excelente es la que puede proporcionar más placer sexual.

11.- Es la interpretación que ofrece Pedro M. Cátedra 1987, en un trabajo que ya es todo un clásico sobre el tema del amor en el siglo Xv. Es verdad que en el monólogo introduce unas reflexiones que se dirían impensables horas antes de la seducción de su amada. Sus razonamientos ya no son los del personaje enajenado y ridículo de los primeros autos. Parece que después de haber logrado su objetivo más prioritario se haya vuelto un ser normal, aunque tan o más enamorado de Melibea que al principio de la obra. Como recuerda con gran acierto mi maestro, Calisto podía haber fingido una locura que ya deja de simular cuando ha satisfecho el deseo que le había impulsado a adoptarla. Desde entonces podía haberle ocurrido algo que no esperaba, que llegara a enamorarse seriamente de una dama a la que en principio sólo se habría propuesto seducir para olvidarla una vez alcanzado ese propósito. Podía ser ese el nuevo tratamiento que Rojas da a su personaje en la Tragicomedia, pero en la última noche lo sigue caracterizando con las mismas prisas y groserías que la de un mes antes.

12.- En su nota final advierte a las damas de esos que adoptan semejante comportamiento y que identifica como "grandes señores» que se presentan antes sus amadas con piel de cordero para atacarlas y dañarlas como verdaderos lobos (Villalobos 2001: 232). 
espera que su amante no actúe con la violencia de siempre para alcanzar el último grado del amor. Nuestro protagonista procede con la misma urgencia que la primera vez al rasgar las vestiduras de su amada para satisfacer rápidamente su lujuria sin pensar en la de su pareja. Melibea le propone otras prácticas sexuales con las que espera poder gozar más de lo que ha gozado en el último mes. Puede haberlas leído en los manuales de teología que las denunciaban, sin entrar en demasiados detalles sobre en que consistían, como motivo de pecado mortal. Es imposible que las haya conocido a través de ciertos libros de sexología que las recomendaban como modo infalible para obtener mayores deleites en las relaciones sexuales $^{13}$. Melibea no descubre nada que no estuviera ya inventado en sexología. En ese sentido, Calisto no ha experimentado ningún cambio de la primera a la última vez, porque se comporta con su dama como si nunca antes la hubiera seducido, con la misma torpeza y falta de tacto que la primera. En el mes que ha transcurrido, sigue padeciendo la misma lujuria que lo había hecho enfermar cuando se encontró causalmente con Melibea en la escena con que empieza la obra. Parece al final tan necesitado de satisfacer ese deseo que le inspiró entonces y que en teoría ya ha satisfecho en reiteradas ocasiones a lo largo de un mes. En teoría, Rojas ha repetido el mismo tipo de escena porque sus lectores, los jóvenes por supuesto, se lo habían pedido, y, aunque no tenía intención de ceder a esas demandas, por la insistencia, ha acabado haciéndolo ${ }^{14}$. Haya sido cual haya sido el auténtico motivo de esa prolongación de su obra, el caso es que ha intentado contradecir la teoría médica de que la curación del amor hereos podía estar garantizada con la práctica del coito con la dama amada o con otra joven que la sustituya para el cumplimiento de la terapia.

El amor no fue considerado propiamente como una enfermedad por la medicina griega, que la catalogó como una pasión del alma que en algún caso podía repercutir en el cuerpo. Por eso ninguno de sus médicos le llegó a dedicar algún capítulo específico en sus manuales o comentarios de otras obras. Galeno expone el caso real del que debió de ocuparse por haberlo llamado el senador romano Justo para que visitara a su esposa que parecía aquejada de alguna enfermedad. El médico griego le practicó una exploración cuyos resultados fueron normales. Pudo diagnosticar el mal que aquejaba a la mujer por notar que su pulso se aceleraba súbitamente cuando vio acercarse a ella un bailarín al que da el nombre de Pilades. No dio a la esposa del senador ninguna terapia para su mal. A lo largo de su relato alude a un caso similar que protagonizó su colega Erasístrato, quien descubrió el mal que había obligado al Antíoco a guardar

13.- En su Summa theologica, santo Tomás incluye los besos, los abrazos y las caricias entre las prácticas que, si se ejecutan con lujuria, pueden constituir pecado moral. En los manuales de sexología, los pocos que se han conservado, insistían en ese tipo de preámbulos si los amantes querían obtener el máximo placer de sus relaciones sexuales.

14.- Véase Morros 2009. 
cama por el mismo procedimiento, al notar la alteración del pulso cuando en la habitación del príncipe entraba su madrastra. Dedujo que Antíoco no estaba realmente enfermo, sino enamorado, y así se lo comunicó al rey, convenciéndole con gran astucia de que lo que debía hacer en ese caso era cederle a la mujer. El padre no dudó en aplicar ese remedio y la repudió para permitir al hijo casarse con ella y devolverle de ese modo la salud. Galeno, en cambio, no hace alusión a la parte final de esa historia, no tanto por pudor, sino más bien porque no debió considerar efectiva la terapia sexual. De hecho, en un comentario a las Epidemias de Hipócrates, no la incluye entre los remedios que sugiere para tratar las alteraciones pisco-somáticas que podía producir el amor ${ }^{15}$.

Los primeros médicos que le consagraron capítulos específicos en sus manuales porque lo identificaron ya como una enfermedad que convenía delimitar claramente fueron los médicos bizantinos y los árabes, traducidos al latín sobre todo por Constantino el Africano. Si unos acabaron clasificándola como una clase de melancolía, otros creyeron que en su origen no lo era pero que si no se atajaba podía acabar produciéndola. Los médicos posteriores, ya de finales del siglo XIII y principios del XV, no se pusieron de acuerdo cuando tenían que relacionarla con la melancolía. Bernardo Gordonio, en su Lilium medicinae (1305), traducido al castellano en 1495, cuando aún Rojas no se había decidido a acabar la Comedia, la llamó hereos (es denominación que ya habían adoptado los traductores latinos de las obras árabes) y la definió como "solicitud melancólica», para la que en principio descartó la terapia sexual, porque pensaba que si el enfermo la practicaba eliminaba las cualidades que necesitaba para recuperar la salud. En otro capítulo, titulado "De la poquedad del coito», había asegurado que el temperamento melancólico no era el más apto para las relaciones sexuales, porque carecía de la cualidad, el calor, que podía hacer que las deseara, y de otra, la humedad, que le garantizara que las pusiera en práctica con la debida energía. Las recomienda, en cambio, para amantes hereos con otros temperamentos, con la condición de que los enfermos la lleven a cabo con moderación ${ }^{16}$. Sin mencionarlos para nada se está refiriendo a los coléricos y sanguíneos, a quienes sin embargo reconoce la posibilidad de contraer una enfermedad más propia de melancólicos. Sin embargo, puede llegarse a contradecir cuando afirma que el amante hereos concibe como su mayor felicidad "alcanzar» a la dama a la que atribuye unas cualidades físicas y morales que no ha sabido reconocer en otras. Si bien no explica en qué consiste ese logro expresado con semejante verbo es fácil imaginar que debe ser de tipo sexual, y el melancólico por naturaleza no experimenta tales aspiraciones por no ser nunca víctima de los deleites carnales. En el apartado de las «curas»,

15.- Véase Wack 1990: 8.

16.- Véase Gordonio 1991: 107, 302 y 109. 
citando a Ovidio, recomienda al enfermo amar a dos mujeres a la vez por si falla una poder disponer de la otra. Parece una medida preventiva con la que quiere evitar que el amante se obsesione por una sola mujer, pero no debe suponer que con la otra que no lo rechaza pueda mantener relaciones sexuales ${ }^{17}$.

Otro médico que había estudiado en Montpellier, Arnaldo de Vilanova, compuso varias obras en las que expuso sus ideas sobre el amor hereos. Una de esas obras precisamente la tituló Tractatus de amore heroico (h. 1280), porque la dedicaba exclusivamente a ese tema. En la definición de amor hereos evita la palabra melancolía y sólo la incluye junto a la de manía como consecuencias de un mal tratamiento de la enfermedad. Deja claro que este tipo de amor lo experimenta quien se ha obsesionado de tal modo de la amada, que le inspira una concupiscencia que tiene la esperanza de poder satisfacer. Para explicar que los sentidos internos no ejercen sus funciones de manera correcta imagina en el enfermo una complexión colérica que seca los tres ventrículos donde cada uno de ellos suelen situarse. Relaciona, por tanto, esa complexión con la concupiscencia desmesurada que llega a sentir quienes la poseen. Afirma que el corazón del enfermo produce más espíritus vitales de los normales a causa de su concupiscencia y que esos espíritus, al llegar en grandes cantidades al cerebro, lo secan. Al carecer sus ventrículos de la humedad necesaria los sentidos que realizan sus operaciones en cada uno de ellos no las pueden ejercer correctamente al estar como emborrachados por tanto calor y sequedad. En ese estado esos sentidos tienden a la exaltación de la dama que ha inspirado en el amante esa concupiscencia desmesurada al verla por primera vez. Pero también fijan con mayor firmeza la imagen que han obtenido de ella por hacerla sobre una sustancia tan seca y poco húmeda como lo es la masa cerebral del enfermo de amor. Por ese motivo Vilanova recomienda encarecidamente la práctica sexual como único modo de desactivar la concupiscencia que produce la enfermedad. Sugiere que el amante la satisfaga con jóvenes con las que experimente el placer que había imaginado conseguir de su dama ${ }^{18}$.

En la otra obra, De parte operativa, Vilanova incluye el amor hereos como una de las cuatro o cinco especies de alienación que llega a distinguir junto a la manía. Insiste en el error en que incurre el sentido interno del amante al juzgar la imagen de la amada como la más excelente, pero en esta ocasión el error es el origen de su concupiscencia porque no cree que haya otra dama con la que pueda conseguir un placer mayor. Cuando se refiere a la complexión del amante hereos la identifica con una que llama venérea y que debe corresponder a la del sanguíneo, porque además del calor le supone la humedad necesaria para la excitación de los órganos

17.- Véase Gordonio 1991: 108.

18.- Todas estas ideas pueden leerse en Villanova 1985: 43-54. 
sexuales. Justifica entonces la concupiscencia por la necesidad o utilidad que tiene de satisfacerla expulsando el humor que se la provoca. Con esa explicación hacía coherente la terapia que considera más eficaz, la de tipo sexual, que podía aplicarse con la amada o con sustitutas con las que el enfermo pueda obtener la misma complacencia carnal ${ }^{19}$. Por lo que respecta al temperamento típico del amante hereos y a la solución para dejar de serlo, Vilanova contradecía las teorías de Gordonio.

El médico y filósofo portugués Pedro Hispano, que ejerció su profesión en Siena y fue elegido papa con el nombre de Juan XXI, compuso unos comentarios a una de esas obras árabes que había traducido Constantino el Africano como el Viaticum. No debió de tener las ideas claras sobre el tema pues llegó a elaborar dos versiones muy diferentes, las dos anteriores a la obra de Gordonio y Vilanova. En esos comentarios utiliza la definición clásica del amor hereos como «sollicitudo melancolica» para dejar claro que el temperamento que lo origina no es el melancólico, porque el enfermo para sufrirlo necesita de un calor que ese temperamento no puede proporcionarle. Sugiere como una de las causas de la enfermedad la abundancia de semen ("copia spermatis») en los testículos del enfermo, y esa reacción fisiológica sólo puede producirse con el calor, nunca con el frío de los melancólicos. Por eso aclara que el amor hereos es una enfermedad más propia de jóvenes que de viejos, y que no suelen padecerla los melancólicos, pues muy poco de los primeros llegan a serlos. Si Avicena la definió como arriba hemos recordado fue pensando no en la materia sino en sus accidentes, porque el futuro papa recuerda que las dos enfermedades tienen síntomas muy similares pero causas muy diversas. Al referirse a la terapia sexual, que aconseja sin vacilación alguna, distingue entre el placer que obtiene cada uno de los dos sexos al ponerla en practica. Llega a la conclusión que el varón la desea con más intensidad, pero que la hembra la disfruta más, porque no sólo expulsa sus humores sino que también recibe los de su pareja ${ }^{20}$. Esta idea la expone también Gordonio en las aclaraciones que cree necesario introducir al final del capítulo dedicado a la enfermedad ${ }^{21}$.

Otro comentarista del Viaticum y médico de Montpellier, Gerardo de Solo, del segundo tercio del siglo XIV, dedicó diversas obras al amor hereos. En su Quaestio de amore hereos, lo define, al igual que Gordonio, como "sollicitudo melancolica", porque lo considera con muchas semejanzas con la melancolía, entre las que destaca esa común obsesión de sus enfermos por una forma o figura bella que acaban deseando. Por eso ex-

19.- Villanova 1520: 273, 270-271 y 286.

20.- Wack 1990: 214-251.

21.- Gordonio 1991: 109 («E por eso los varones porque son más calientes, mucho más deleitan en el coito, e las mujeres mucho más se deleitan en la esperma del varón e en la suya propia»). 
plica que el amor hereos también se origina por un error de uno de los sentidos internos como consecuencia de la frialdad y sequedad del ventrículo o concavidad en que lleva a cabo sus operaciones. A diferencia de Villanova, presupone una dispositio melancólica que explica el fallo de ese sentido interno. En cuanto a la terapia se contradice al asegurar, citando a Avicena, que es una enfermedad difícil de curar si no es con la unión del amante con su amada a través de la ley y la fe, esto es, a través del matrimonio. Sin embargo, un poco después se refiere al consejo que pueden proporcionar ciertas muchachas («consilium puellarum»), con quienes no descarta la relación sexual ("plurimum ipsarum concubitus»)22. En su comentario al libro IX de Almansor, incluye el amor hereos como una tercera especie de melancolía, pero lo distingue de otros por ser más intenso y fuerte a causa de las ganas del amante de practicar el coito con la mujer que se lo inspira. Esta vez el error del sentido interno lo produce una complexión sanguínea, porque supone en el enfermo una abundancia de semen que estimula ese sentido no sólo a juzgar inadecuadamente a la amada, sino a desearla carnalmente. Más adelante admite que el amor hereos lo puede sufrir cualquier tipo de hombre, pensando en sus temperamentos. Menciona a los melancólicos por su imaginación que cree acentuada por la abundancia de su humor (lo llama "materia»), que le hace poder mucho y desear poco ("que multum possunt, sed non appetant»); Incomprensiblemente descarta a los coléricos porque pueden poco a pesar de desear mucho. Diferencia el coito del hombre del de la mujer porque uno necesita calor y la otra frialdad. Afirma que el deleite del coito es más intenso en el varón y más duradero en la mujer; en el primero porque disfruta al eyacular y al tocar, mientras la segunda en la emisión de su semen y en la recepción del de su pareja, más perfecto, pero también en el movimiento de su matriz hacia la vulva para permitir la introducción del órgano masculino, cuyo roce con el cuello de aquélla produce mucho placer (en ese punto se refiere a las meretrices, ricas y pobres, que lo son porque les apetece por esa razón practicar la relación sexual ${ }^{23}$. Para no contradecirse al tratar el amor hereos como una clase de melancolía y sugerir a su vez para su cura la terapia del coito, comete el error de atribuir a su temperamento las mismas cualidades que el flemático, al que no cita como susceptible de padecer la enfermedad. Queriéndola evitar, acaba incurriendo en la contradicción al afirmar que el coito necesita calor y negárselo al melancólico cuando lo presenta con muy poco deseo. En el libro sexto del Viaticum, dedicado a cuestiones andrológicas y ginecológicas, incluye el pasaje en que su autor se refiere al deseo y poder sexual que tienen los diferentes temperamentos. Ibn al-Jazzar asegura que para el coito sea perfecto no ha variar la compleción de los testículos.

22.- Solo 1526: 100 vo

23.- Solo 1526: 34 ro. 
Si en ellos domina el calor y sequedad, entonces habrá poco esperma y mucha concupiscencia; si prevalece la frialdad y la sequedad, habrá poco esperma y una concupiscencia defectuosa; si prepondera la frialdad y la humedad, entonces habrá mucho esperma pero poca concupiscencia; antes el autor árabe había afirmado que la complexión cálida y húmeda es la ideal para el coito, porque el calor aumenta la concupiscencia y la humedad el esperma ${ }^{24}$.

El médico portugués Valesco de Taranta, en una obra de comienzos del siglo XV que se hizo muy famosa y que tituló Practica medicina que alias Philonium dicitur, siguió más la línea de Vilanova y su compatriota que la de Gordonio, pero, como Gerardo de Solo, no llegó a descartar a ninguno de los cuatro temperamentos como víctimas de la enfermedad de amor que también denominó hereos. Lo define como un amor irracional que se siente hacia una mujer con la intención de seducirla. Por eso como primera medida aconseja entregársela al enfermo, dando a entender que se la pone en sus manos para que la rinda sexualmente. Confirma esa interpretación cuando más adelante alude a la utilidad del coito incluso cuando el enfermo no lo pone en práctica con la dama a la que desea. En ese caso recomienda que las que cumplan con esa función no sean repugnantes y malolientes para no dar pie a las comparaciones con la amada. También insiste en que el coito, sea con quien sea, el enfermo lo debe realizar muchas veces cuando se halla en un estado cercano a la muerte. Sin embargo, también propone los besos y conversación con determinadas damas entre las que el amante deberá elegir una para casarse si quiere llegar más lejos en su relación. Ese consejo no encaja con el primero en el que no aludía para nada al matrimonio cuando sugería proporcionarle al enfermo a la mujer a la que amaba. Si distingue entre dos clases de sustitutas, unas para el sexo y las otras solo para los besos, es que quería dejar claro que las primeras debían escogerse entre el mundo de la prostitución y las segundas entre el de la aristocracia. Si con esas últimas se deseaba la práctica sexual entonces con las primeras se planteaba el matrimonio. Ese mismo planteamiento debía de hacerlo para la amada, que cabe dar por supuesto que pertenecería también a la alta nobleza. No descarta la posibilidad de recurrir a unas viejas que se han especializado, ejerciendo la hechicería, tanto en el arte de enamorar como el de desenamorar. Entre las aclaraciones finales introduce una reflexión sobre los distintos temperamentos que tienen mayor o menor susceptibilidad de padecer el amor hereos. Incluye como los que más a los sanguíneos y coléricos, de quienes pronostica una rápida curación por poderles aplicar la terapia sexual. Extrañamente en el grupo de los propensos a contraer la enfermedad añade a los melancólicos, en quienes cree muy acentuado el poder de imaginación, como queriendo dar a entender que por ese motivo se ena- 
moran más fácilmente. Sin embargo, los considera más difíciles de curar porque no pueden quitarse de su mente a la dama a quien imaginan con las mejores cualidades. Si bien no llega a afirmarlo, parece estar pensando que su curación se complica al no poderles aplicar la terapia sexual por ser incompatible con su complexión. No obstante, había acabado la serie de terapias asegurando que el coito también beneficiaba a los melancólicos y maniáticos, porque les permitía eliminar la materia adusta que los excitaba.

Conocedor de la obra de Taranta es el médico extremeño Francisco López de Villalobos, quien la utiliza como modelo para su Sumario de medicina, publicado en Salamanca en 1498. No sé si Rojas llegó a leer el libro editado antes de acabar la Comedia, pero pudo conocer una versión manuscrita dada la posibilidad de que los dos autores llegaran a coincidir en la universidad salmantina. Villalobos incluye el capítulo del amor hereos antes del dedicado a la melancolía y la manía, al igual que había hecho el médico portugués, para dejar clara su postura de que una enfermedad podía dar origen a las otras dos pero no al revés. Se salta la definición y pasa directamente a la exposición de las causas del amor hereos, entre las que señala el error de uno de los sentidos internos que determina el mal funcionamiento de los demás. El sentido en cuestión emite un falso juicio sobre la amada que condiciona que los otros sentidos no hagan otra cosa que representársela día y noche. El falso juicio provoca un gran fuego en el corazón del amante que su deseo no deja de atizarlo en todo momento. Por tal razonamiento se diría que Villalobos no contempla la posibilidad de que la melancolía propicie las condiciones necesarias para el desencadenamiento del amor hereos. En el apartado "De la cura» omite la primera que da su modelo, porque la debe creer ambigua, por lo que respecta a hacer entrega al enfermo de la dama deseada sin especificar con qué propósito. En su lugar, como octavo remedio, aconseja que lo aparten de ella como de la peste: "octavo le aparten... de aquella señora como en pestilencia...». En semejante consejo no ha hecho más que aplicar literalmente otro del mismo Taranta en que el médico portugués lo proponía como una huida en caso de no ser posible la correspondencia por parte de la amada («recedere a dilecta sicut ab aere pestilentiali»). Recomienda la relación sexual con prostitutas o con una dama a través del matrimonio. Se refiere también a las viejas que puedan aplicar sus habilidades en la hechicería para desenamorar a los enfermos, a quienes sin embargo no ofrece la posibilidad de que esas mismas viejas empleen sus argucias para enamorar a la dama que ha causado la enfermedad y que se ha empeñado en rechazarlos. Por último, aconseja una dieta rica en sangre, seguramente pensando en los melancólicos que sufren déficit de ese elemento y que pueden llegar a practicar el coito ${ }^{25}$. 
En la última nota que introduce en la escena final de su traducción comentada del Anfitrión de Plauto, publicada en Alcalá de Henares en 1517, Villalobos enumera las diferentes clases de amor para detenerse en el que ya había definido en su libro de medicina. Ahora no lo llama hereos pero lo considera, al igual que Vilanova, una especie de alienación, por la que el amante deja de ser él mismo para convertirse en la amada. Explica este fenómeno por el mal funcionamiento del sentido interior que se encarga de componer las imágenes y que parece elaborar una falsa de la amada que hace que no pueda borrarla de su mente en ningún momento del día ni de la noche. Se refiere a un humor responsable de ese error del sentido interior del amante pero no lo llega a concretar en ninguno de los cuatro que distinguía la medicina. No parece pensar en el colérico porque presenta a estos amantes alienados como muy mansos a quienes cualquiera puede acercarse sin temor de ser atacado y con quienes puede divertirse hablando de sus obsesiones. No propone ninguna terapia, pero insiste en que estos amantes no quieren recuperar su salud porque se complacen en la locura que los mantiene enajenados. Sin embargo, al final no los llama locos desvariados, sino galanes a quienes distingue de otros a los que denomina fingidos, porque aparentan ser víctimas de la misma alienación para conseguir engañar a sus damas y de ese modo seducirlas. No puede evitar contradecirse porque da a entender que los temperamentos de estos amantes pueden ser o melancólicos o flemáticos, pero les supone un calor que ninguno de ellos posee para justificar la enajenación que padecen al juzgar y retener una imagen que de ser fríos y húmedos podrían fácilmente hacer desparecer.

De la primera mitad del siglo XV conservamos una obra de un teólogo, Alonso del Madrigal, más conocido como el Tostado, en que hace referencia al amor que los médicos llaman hereos. La obra la titula Breviloquio de amor e amicicia y en sus páginas distingue dos clases de amor libidinoso, el que pretende saciar el deseo carnal con cualquier mujer, porque sólo lo mueve el fuego de la lujuria, y el que pretende satisfacerlo con una dama en concreto, la que los sentidos internos, entre ellos la imaginación, del amante han elegido como excelente. A este segundo tipo de amor lo identifica con el amor hereos y asegura que éste, y no el otro, es el más difícil de extinguir, porque la lujuria puede apagarse con mucha facilidad, pero la que la inspira esa imagen excelente obtenida de la amada no se satisface de cualquier manera, porque el amante no la borra así como así de su mente. Por eso, en el capítulo final de los remedios, no contempla la posibilidad de la terapia sexual, porque sólo pude serle útil a los movidos por la simple lujuria del alma vegetativa, pero de nada o poco sirve a los amantes en cuya lujuria participa el alma sensitiva. Descarta por esa razón el consejo que da Ovidio sobre la conveniencia de elegir a diversas mujeres para repartir así su amor y restarle la fuerza que tendría concentrado en una sola. Como no es médico, el Tostado no habla de tempera- 
mentos, pero sólo considera víctimas de esas dos clases de amor que ha descrito a los mancebos a quienes se las supone especialmente por edad, más cerca de los temperamentos sanguíneo y colérico, por compartir con ellos el calor que les hace padecer la lujuria más que en otras edades o anteriores o posteriores.

Rojas parece compartir la teoría de Gordonio de que la terapia sexual no es eficaz para combatir el amor hereos. Ha creado, aunque no él solo, a un personaje que se enamora de una dama de la que sigue enamorado después de un mes de tener relaciones sexuales con ella cada una de sus noches. Es un personaje que caracteriza con un temperamento alegre que tras el rechazo de su dama se vuelve triste. En ese nuevo temperamento no ha dado muestras de una absoluta tristeza, sino más bien de una locura producto de la lujuria que parece inspirarle su dama. En el diálogo con uno de sus criados ha sido capaz de reírse por el chiste que su interlocutor ha hecho sobre el tipo de pecado que le llegaba a imputar. También ha tocado el laúd y ha salido a pasear montado en su caballo. Ha exhibido una lujuria desmesurada al querer satisfacer su deseo con el cordón de su amada llegando a confundir la prenda con su dueña. Si bien es verdad que se ha pasado una noche y una mañana entera hasta la hora de mediodía tumbado en la tarima de su habitación sin saber si era de noche o de día o que se ha pasado la tarde de ese día en la iglesia rezando, su conducta no ha sido del todo apática. Si con alguna de las actitudes que le hace adoptar podía presentarlo como un melancólico desde la segunda escena de la obra, con otras que también le atribuye desde entonces parece distinguirlo como un colérico e incluso un sanguíneo, especialmente por la lujuria e ira que pone de manifiesto en determinados episodios. En esa indefinición podía haber dado muestras de una melancolía adusta, que llegaría a justificar todos los estados de ánimo que tiene hasta la rendición sexual de su dama. De ser así, tendría cierta lógica que tras lograrla se sintiera víctima de la misma lujuria que el día anterior, porque el melancólico adusto nunca llegaba a satisfacerla del todo por faltarle la cualidad, que es la humedad, con que podría haberlo hecho. Por ese motivo, la última noche habría demostrado la misma urgencia sexual con su dama que la primera vez que no pudo disimularla cuando le arrebató la virginidad. Con esa reiterada torpeza, al menos en el arte de la seducción, ha provocado todas las veces las quejas de una dama que en ese momento no se siente satisfecha por el tipo de sexualidad al que ha sido obligada por culpa de las prisas de un amante más vehemente que dulce. En semejantes condiciones, nuestro protagonista no parece poder garantizar grandes proezas sexuales. Sin embargo, la última noche, los encuentros sexuales con su dama parece narrarlos Lucrecia, quien se los imagina en la oscuridad, porque sólo puede oírlos hablar y gemir, pero difícilmente abrazarse y besarse. Cuando después de tanto ruido se impone el silencio entre los amantes, la criada no puede menos que decir "¡Andar, ya 
callan! A tres me parece que va la vencida». Ningún editor ni crítico ha dudado que con ese «tres» Lucrecia se refiere a las veces que su señora y amante habían mantenido relaciones sexuales, queriendo dejar claro que después de ese número las habían dado ya por acabadas. Antes, la criada ha introducido una observación similar al oír que su señora no dejaba de protestar por los modales de Calisto: "Ya, ya, apaciguado es el ruido: no hubieron menester despartidores». En este caso, debe entenderse que después de las riñas los dos amantes habían decidido poner en práctica el coito. Por eso, tras consumarlo, Melibea le ofrece a su amante una pequeña colación con la que poder recuperarse. Calisto la rechaza y parece empezar de nuevo el acoso de su amada, a quien, a pesar de sus protestas, vuelve a rendirla. Por mimesis con el anterior, la criada se habrá referido a que tampoco está vez han sido necesarios los despartidores porque las riñas entre los amantes han dado lugar a un segundo coito. Podía haber empleado la expresión "A la de tres va la vencida» para aludir no al número de encuentros sexuales sino al de las riñas antes de consumar uno diferente al anterior.

En esas dos posibles interpretaciones de esa última noche de amor, los amantes habrían mantenido entre dos y cuatro relaciones sexuales. Para las exageraciones a las que no tienen acostumbrados los autores medievales ninguna de las dos cifras sería para considerar a Calisto un superdotado. Desde una perspectiva médica, la primera formaría parte de la moderación que podían exigir a quienes se la prescribiera por cuestiones de salud, mientras que la segunda ya habría superado el límite aconsejable en semejantes casos de debilidad. Si, además, tenemos en cuenta que Calisto ha visitado cada una de las noches de todo un mes el huerto de Melibea, el número de coitos en ese período habría sido importante. Pero Melibea deja claro que no todas las noches han podido practicarlos, porque confiesa a Lucrecia, que ya debe saberlo, que muchas su amante ha ido en balde. No aclara el motivo de semejante impedimento, y las especulaciones al respecto han sido variadas. Para una mayoría, Melibea podría aludir a la semana del mes en que habría tenido la regla; otros opinan que la muchacha no habría estado dispuesta a plegarse cada noche a los deseos de su amante; y aun unos terceros están convencidos de que la hija de Pleberio podría referirse a los escuderos de su padre que habrían hecho durante esas noches la ronda por el huerto de su casa. Sin embargo, hay una cuarta posibilidad que nadie parece haber contemplado. La de que no todas las noches Calisto hubiera podido satisfacer su lujuria por tratarse de un melancólico adusto, temperamento bastante limitado a la hora de ponerla de manifiesto.

Si seguimos pensando que Rojas se ha inspirado en la obra de Gordonio para aplicar sus ideas sobre la enfermedad de amor, podríamos llegar a la conclusión de que Calisto no se cura de su amor hereos por haber abusado de una terapia que el médico de Montpellier había negado a 
los melancólicos naturales y sugerido con mucha moderación a los otros temperamentos en los que estaba indicada. También podríamos proponer que el toledano tuvo más en cuenta la obra de Valesco de Taranta en que se aconsejaba "multotiens» el coito cuando el enfermo estaba en peligro de muerte. Ese riesgo Rojas lo hace predecir a alguno de los criados de su protagonista, y quizá por eso había introducido tantas ambigüedades sobre las noches que realmente Calisto visitó el huerto de su amada. Según esa segunda interpretación, nuestro amante no se habría curado por no haber practicado demasiadas veces la relación sexual con su amada. A su favor, aunque no para corroborarla, podríamos recordar que Rojas rehúye en el texto la palabra melancolía o algunos de sus derivados, sobre todo cuando después del primer encuentro sexual con Melibea, de nuevo en su habitación, presenta a Calisto poseído por una "solicitud» que evita calificar para no identificar la enfermedad de su personaje con la melancolía. Y si no lo ha hecho, es porque era consciente de que la natural no podía justificar la lujuria de Calisto en cada episodio de la obra, de principio a fin

La Celestina es una obra tan abierta, que permite la aceptación de esas dos interpretaciones, y seguramente de alguna más. Si pensamos en su vertiente más moralista, quizá deberíamos aceptar la primera, porque con ella su autor habría querido disuadir a sus lectores jóvenes de creer que el amor se curaba con la práctica de una terapia sexual. De haber querido vender esa versión del amor hereos sabía que se exponía a más críticas de las que acabó recibiendo. Puso en boca de la alcahueta las tesis naturalistas de que el amor es un sentimiento natural y que turba a quien lo experimenta precisamente por el deleite que espera obtener con su realización. Sin embargo, Celestina justificaba el deleite como un acicate que puso Dios a los seres humanos para que de ese modo perpetuaran la especie. Rojas ese acicate no se lo atribuyó ni a Calisto ni a Melibea, porque de sus relaciones sexuales no se deriva la procreación sino la recreación en el propio deleite (otra cosa es que lo lleguen a conseguir). El padre de la heroína ha dedicado su juventud al amor puramente carnal y, al inaugurar la vejez, lo había abandonado para casarse con Alisa y procrear enseguida a su hija. Calisto y Melibea pertenecen a la edad que tienen los destinatarios de la obra que protagonizan: la de los mancebos que no desean más que experimentar los placeres propios de su edad, a los que les cuesta renunciar precisamente porque su lujuria la ha despertado el falso juicio que sus sentidos internos han acabado obteniendo el uno del otro. Como creía el Tostado, ese falso juicio no se borra con la simple relación sexual, porque lo supone resistente a su consumación. Un buen ejemplo de esa teoría es Calisto, pero también Melibea, que acaba contagiada de la misma enfermedad de su amante al describirlo a su padre, una vez ya ha fallecido, como el dechado de una cortesía que nunca supo reconocerle en vida. Que Calisto no parece haber cambiado lo corrobora el monó- 
logo que dice al regresar a su casa tras haber estado con su amada. No se muestra exultante porque se convence de que sólo momentos después de haberse separado de ella ya la echa en falta. Tras una larga reflexión sobre la actuación del juez a quien acaba justificando pide a su fantasía que le represente las escenas eróticas que ha vivido momentos antes con Melibea. Las recuerda muy distintas a cómo en realidad sucedieron porque en ningún momento alude a las reiteradas quejas que su amada había puesto de manifiesto. La evoca como una doncella que intenta reprimir una lujuria a la que, a pesar de su resistencia, acaba cediendo. Da la impresión de que Calisto ha magnificado esa primera noche con la dama de sus sueños al atribuirle unas actitudes que cuando se produjeron no supimos notárselas ni tan siquiera adivinarlas. Si en realidad ha cambiado en algo es en imaginarse las relaciones sexuales con su dama como las mejores que ha podido tener. De hecho, termina el monólogo deseando que pasen las horas rápidamente para volver a repetirlas de nuevo. A partir de ese momento de la obra Calisto sólo piensa en el placer sexual que puede proporcionarle la hija de Pleberio. Incluso se convence de que su conducta ha sido más pasiva de lo que ha dado a entender su amada al reconvenirle que no se hubiera demorado en unos preámbulos y en un juego erótico que sin duda nuestro héroe se había saltado. Al hallarse ante Melibea no ha dudado en alcanzar el último grado del amor sin detenerse en los cuatro anteriores. En su fantasía, sin embargo, se los representa como si los hubiera seguido todos hasta llegar al último.

Sirviéndose de las teorías médicas que las obras analizadas podían haber puesto a su alcance, tanto el antiguo autor como Rojas pretendieron parodiar el amor que los autores cortesanos habían exaltado en sus obras. Por tal motivo atribuyeron a su personaje una lujuria que el amante cortés, si bien podía haber sentido, siempre había sabido disimular (Amadís, por ejemplo, sólo se la da a conocer a Oriana, quien también la experimenta y decide saciarla cuando encuentra el momento adecuado). Tampoco el antiguo autor y Rojas pudieron hacer que compartiera el sacrificio y el desinterés que el modelo que caricaturiza siempre pone de manifiesto en beneficio de la amada. De modo que decidieron crear un personaje muy egoísta que pensara más en sus necesidades sexuales que en el perjuicio que al intentar satisfacerlas podía ocasionar a la dama que se las había despertado. En ese sentido consideran oportuno que la llegue a idealizar tanto como si fuera un amante cortés pero tratándola sin diferenciarla de las mujeres que se pueden comprar con dinero y no como una dama con quien debía haber exhibido unos modales más acorde con su condición social. Sin embargo, Rojas quiere que su protagonista sea víctima de un sentimiento que su modelo también sufre, el de la asunción de un amor más firme y sincero después de su primer relación sexual con la amada que se lo llega a inspirar. Ése es el caso de Euríalo, Amadís y Tirant lo Blanc. Si en esos personajes el mayor amor después de la seducción de 
sus amadas no tiene más explicación que la fidelidad irrenunciable hacia ellas, en el caso de Calisto parece haberse producido más por cuestiones fisiológicas, por estar dotado de un temperamento que hacía imposible que pudiera extinguir un amor que necesitaba de las cualidades propias del sanguíneo para poderlo conseguir. Por eso sus creadores no han querido identificarlo con un melancólico a secas, porque conocían que ese tipo de persona no habría podido sentir la lujuria con que lo han caracterizado desde la primera a la última escena de la obra. 


\section{Bibliografía}

Abano, Pedro, Expositio problematum Aristotelis cum textu, Venecia, 1482.

Amasuno, Marcelino V., "Hacia un contexto médico para Celestina: dos modalidades curadoras frente a frente», Celestinesca, 23. 1-2 (1999), pp. 86-124.

-, "Hacia un contexto médico para Celestina: Sobre amor hereos y su terapia», Celestinesca, 24 (2000), pp. 135-69.

-, "Calisto, entre amor hereos y una terapia falaz», Dicenda. Cuadernos de Filología Hispánica, XVIII (2000), pp. 11-49.

-, «Parodia y patología erótica en La Celestina: el binomio Calisto-Sempronio", en Actas de la Asociación Hispánica de Literatura Medieval, eds., M. Freixas, S. Iriso y L. Fernández,,Santander, Consejería de Cultura del Gobierno de Cantabria-Año Jubilar Lebaniego-Asociación Hispánica de Literatura Medieval, 1, 2000, pp. 153-74.

-, "La enfermedad de Melibea: dos perspectivas médicas de la Aegritudo amoris en Celestina», Revista de Filología Española, LXXXI.1-2 (2001), pp. 5-47.

BeLtrÁn LlaVAdor, Rafael, "Áspera et inurbana verba: la ira de Melibea y Carmesina y la lección desoída de Andreas Capellanes", en Sudia in honores Germán Orduna, Alcalá de Henares, 2000, pp. 73-89.

CÁtedra, Pedro M., Amor y pedagogía en la Edad Media, Salamanca, Universidad de Salamanca, 1989.

Castells, Ricard, "On the cuerpo glorificado and the vision divina», Romance Notes, 34 (1993), pp. 97-100.

- Fernando de Rojas and the Renaissance Vision: Phantasm, Melancoly, and Didactism in "Celestina», Penn State Sudies in the Romance Literatures, 2000.

Ciavolella, M., La malaltia d'amore dall'Antichità al Medioevo, Bulzoni, Roma, 1976.

De Armas, Frederick, "La Celestina: an example of love melancholy», Romanic Review, 66 (1975), pp. 288-295.

Fraker, Charles, "The four humors in Celestina", Approaching the Fith Centenary, eds. Ivy Corfis y Joseph T. Snow, Madison, HSMS, 1993, pp. 128-154.

Gordonio, Bernardo, Practica seu Lilium medicinae, Lyon, 1491. 
-, Lilio de la medicina. Edición crítica de la versión española, Sevilla, 1495, edd. John Cull y Brian Dutton, Madison, Seminary of Medieval Studies, 1991.

Jacouart, D., y Thomasset, C., Sexualidad y saber médico en la Edad Media, Labor, Barcelona, 1989.

LACARRA, Eukene, "Calisto y el amor hereos», Ínsula, 633 (1999), pp. 300302.

-, "La ira de Melibea a la luz de la filosofía moral y del discurso médico», en Cinco siglos de "La Celestina", ed. Rafel Beltrásn y José Luis Canet, Valencia, Universidad de Valencia, 1997, pp. 107-120.

Lucena, Luis, Repetición de amores, ed. Miguel M. García Bermejo, en Tratados de amor en el entorno de Celestina (siglos XV-XVI), dir. Pedro M. Cátedra, Madrid, Ediciones Nuevo Milenio, 2001.

Madrigal, Alfonso, Breviloquio de amor e amicitia, ed. Pedro M. Cátedra, en Tratados de amor en el entorno de Celestina, pp. 13-30.

Morros Mestres, Bienvenido, "La difusión de un diagnóstico de amor desde la antigüedad a la época moderna", Boletín de la Real Academia Española, LXXIX (1999), pp. 93-150.

-, "Mira a Bernardo' y los autores de La Celestina», Medioevo Romanzo, 26.2 (2002), pp. 296-310.

—, "La Celestina como remedium amoris», Hispanic Review, 72 (2004), pp. 77-99.

-, "Los prólogos en prosa de La Celestina», Celestinesca, 33 (2009), pp. 115-125.

—, "Las dos primeras escenas en el ms. de Palacio», Medioevo Romanzo, en prensa.

-, "Melancolía y amor hereos en La Celestina», Revista de Literatura Medieval, en prensa.

Nifo, Agostino, Libri duo: de pulcro primus, de amore secundus, Lyón, 1549.

Peri, M., Malato d'amore. La medicina dei poeti e la poesia dei medici, Rubbetino, Messina, 1996.

Piccolomini, Eneas Silvio, Historia de duobus amantibus, ed. Donato Pirovano, Edizioni dell'Orso, Roma, 2004.

-, Historia muy verdadera de dos amantes, ed. Ines Ravasini, en Tratados de amor en el entorno de Celestina, pp. 167-217.

-, Estoria muy verdadera de dos amantes, ed. crítica de Ines Ravasini, Bagatto, Roma, 2003.

Rojas, Fernando, La Celestina, ed. Bienvenido Morros, Barcelona, VicensVives, 1996.

—, La Celestina, ed. María Eugenia Lacarra, Madison, The Hispanic Seminary of Medieval Studies, 1995.

- (y «antiguo autor»), La Celestina. Tragicomedia de Calisto y Melibea, edd. Francisco J. Lobera, Guillermo Serés et alia, Barcelona, Crítica, 2002. 
SeArs, Teresa A., "Bernardo Gordonio' Lilio de la medicina. A posible Source of Celestina», Celestinesca, 10 (1986), pp. 13-18.

Solo, Gerardo de, Opera, Venecia, 1526.

Taranta, Valesco, Practica medicae que alias Philonium dicitur, Lyon, 1490.

-, Practica medicae que alias Philonium dicitur, Lyon, 1535.

TomÁs, santo, Summa Theologica. III. Secunda secundae, Biblioteca de Autores Cristianos, Madrid, 1963.

Vilanova, Arnaldo, De parte operativa, en Opera superrima revisa, Lyon, 1520, fol. 252-294.

- Tractatus de amore heroico, en Opera medica omnia, ed. Michael R. McVaugh, Universidad de Barcelona, Barcelona, 1985, pp. 43-54.

Villalobos, Francisco López, El Sumario de Medicina con un tratado de las pestíferas bubas, ed. María Teresa Santander, Salamanca, Universidad de Salamanca, 1973.

- Sentencias de amor, ed. Pedro M. Cátedra, en Tratados de amor en el entorno de Celestina, pp. 223-246.

Wack, Mary F., "'Ali ibn Al-'Abbas Al-Magusi and Constantine on Love, and the evolution of the Practica Pantegni», en Constantine The African and'Ali ibn Al-'Abbas Al-Magusi, edd. Charles Burnett y Danielle Jacquart, Brill, Nueva York, 1994, pp. 161-202.

-, Lovesickness in the Middle Ages. The "Viaticum» and Its Commentaries, Philadelphia, University of Pennsylvania Press, 1990.

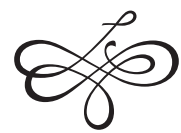




\section{Morros Mestres, Bienvenido, «La melancolía de Calisto», Celes- tinesca, 34 (2010), pp. 75-97.}

\section{RESUMEN}

Rojas evita mencionar la palabra melancolía porque no quiere incurrir en la contradicción de relacionar ese temperamento con la enfermedad de amor que ha decidido atribuir a su protagonista. Estaba al corriente de las ideas que al respecto habían formulado los médicos más importantes de la Edad Media. De todas ellas comulga con las que había sostenido Bernardo Gordonio en su obra titulada Lilio de la medicina. El profesor de Montpellier había creído que la terapia sexual no era demasiado eficaz para combatir la enfermedad de amor porque la provocaba un temperamento, el melancólico, poco apto para su práctica. En la Celestina, no acaba de estar claro por qué Calisto no se ha curado de su enfermedad: si por haber practicado poco o mucho la terapia sexual.

PALABRAS Clave: Celestina, melancolía, enfermedad de amor, medicina medieval, literatura del siglo XV.

\section{ABSTRACT}

Rojas avoids mentioning the word melancholy because they want to incur the contradiction of that temperament relate to the disease of love that has decided to allocate its protagonist. Was aware of the ideas that had been made about the most important doctors of the Middle Ages. Of all communes with those that had sustained Gordonia Bernardo in his work entitled Lilio of medicine. Montpellier professor had believed that sex therapy was not very effective against disease caused love because the temperament, the melancholic, unsuitable for practice. In the Celestina, not just to be clear why Callisto has not been cured of their disease: if you have practiced little or a lot of sex therapy.

KEY WORDS: Celestina, melancholy, love sickness, medieval medicine, literature of the fifteenth centur . 